\title{
A RESPONSABILIDADE CIVIL DAS AGÊNCIAS DE VIAGENS NOS CONTRATOS DE TRANSPORTE AÉREO
}

\author{
CIVIL LIABILITY OF TRAVEL AGENCIES IN AIR TRANSPORT \\ CONTRACTS
}

\author{
Pedro Guilherme Galinari Costa Faria ${ }^{1}$ \\ Júlio Moraes Oliveira ${ }^{2}$
}

\begin{abstract}
RESUMO: Este artigo tem como objetivo analisar a responsabilidade das agências de viagens e turismo perante os contratos de transporte aéreo. A expansão e massificação das relações comerciais foram pano de fundo para o crescimento e surgimento de novas empresas, produtos e serviços. Neste sentido, restou necessário uma tutela específica que protegesse a parte hipossuficiente da relação, fato que gerou o nascimento do Direito do Consumidor. As relações que envolvam os contratos de transporte aéreo são tipicamente de consumo, contudo, há necessidade de se analisar a responsabilidade dos fornecedores envolvidos na cadeia de consumo. Portanto, se analisará as decisões do Superior Tribunal de Justiça e das instâncias ordinárias sobre a responsabilização das empresas que prestam serviços no comércio de transporte aéreo.
\end{abstract}

PALAVRAS-CHAVE: Direito do Consumidor. Responsabilidade Civil. Agências de Turismo. Transporte Aéreo.

\begin{abstract}
This study intends to analyze the liability of travel agencies towards aerial transport contracts. The expansion and massification of commercial relationships were the background for the growth and creation of new companies, products and services. In this sense, a specific guardianship that protected the hypo sufficient part of the relationship became necessary, which led to the creation of the Consumer Law. The juridical relationship involving aerial transport contracts are always categorized as a consumer relationship, however, there is a need to analyze the liability of suppliers involved in the consumption chain. Therefore, this study will analyze the decisions from the Superior Court of Justice and from the ordinary courts on the accountability of companies that provide services in the aerial transport market.
\end{abstract}

KEYWORDS: Consumer Rights. Civil responsability. Travel Agencies. Aerial Transporte.

SUMÁRIO: 1 Introdução. 2 Da Evolução Histórica da Responsabilidade Civil. 3 Dos Princípios do Código de Defesa do Consumidor; 3.1 Princípio da Transparência; 3.2 Princípio da Confiança; 3.3 Princípio da Indisponibilidade de Aplicação das Normas de Direito do Consumidor; 3.4 Princípio da Boa-Fé. 4 Da Oferta e Publicidade nas Relações de Consumo; 4.1. Os Princípios da Publicidade; 4.2 O Ilícito Civil na Publicidade. 5 A Relação Jurídica de Consumo. 6 A Teoria da Qualidade no Código de Defesa do Consumidor; 6.1 Introdução; 6.2 A Responsabilidade Pelo Fato do Produto e Serviço; 6.3 A Responsabilidade Pelo Vício do Produto ou Serviço. 7 Dos Contratos de Transporte Aéreo; 7.1 Do Complexo Normativo dos Contratos de Transporte Aéreos; 7.2 Das Agências de Viagens e Turismo. 8 Da Responsabilidade Civil das Agências de Turismo. 9 Considerações Finais. Referências

\footnotetext{
1 Discente da Escola de Direito do Centro Universitário Newton Paiva.

2 Advogado; Professor Universitário; Mestre em Instituições Sociais, Direito e Democracia pela Universidade FUMEC; Especialista em Advocacia Civil pela Escola de Pós-Graduação em Economia e Escola Brasileira de Administração Pública e de Empresas da Fundação Getúlio Vargas EPGE/FGV e EBAPE/FGV; Bacharel em Direito pela Faculdade de Direito Milton Campos - FDMC; Membro do Instituto Brasileiro de Política e de Direito do Consumidor (BRASILCON); Autor e coautor de livros jurídicos e artigos jurídicos nas principais revistas especializadas do país; Parecerista da Revista Quaestio Iuris da Faculdade de Direito da Universidade do Rio de Janeiro (UERJ).
} 


\section{INTRODUÇÃO}

O presente trabalho tem como discussão a responsabilidade das agências de turismo nos contratos de transporte aéreo.

As fontes utilizadas para elaboração do presente artigo científico foram as doutrinas de Júlio Moraes Oliveira, Claudia Lima Marques, Antônio Herman V. Benjamin, Leonardo Roscoe Bessa e Leonardo de Medeiros Garcia, principalmente. Acrescenta-se que a base argumentativa sobre a efetiva responsabilidade das agências de turismo se deu através da análise das jurisprudências dos Superior Tribunal de Justiça (STJ) e demais instâncias ordinárias.

O tema surge com o crescimento e massificação das relações de consumo que foram responsáveis pelo surgimento de diversas empresas, serviços e produtos no comércio. Ao lado disso, o direito precisa acompanhar a evolução das sociedades de massa e tutelar as novas relações jurídicas e comerciais, a partir da busca da segurança jurídica e quebra de desigualdades.

A evolução histórica da responsabilidade civil é o ponto de partida, uma vez que é necessário se descobrir a origem da responsabilização contratual cível e, posteriormente, consumerista.

As novas relações jurídicas e a massificação do comércio, conforme dito, foram essenciais para o surgimento de uma nova tutela jurídica, ora o Direito do Consumidor. A característica constitucional e a importância do Direito do Consumidor tornaram-no um ramo autônomo do Direito, fato que gera ao ramo doutrinas e princípios próprios, conforme será estudado.

Além disso, a especificidade do contrato de consumo, bem como a vulnerabilidade conceitual do consumidor são elementos essenciais para tutela específica e sólida de alguns direitos, tais como os relacionados a publicidade consumerista. Portanto, se fez necessário um estudo doutrinário sobre a publicidade nas relações de consumo.

Encerra-se a discussão da essência dos contratos de consumo e passa-se a discorrer sobre as agências de viagens e turismo e a responsabilização na relação de consumo, a partir da teoria da qualidade.

Por fim, aplica-se todo conteúdo doutrinário no estudo das jurisprudências que tratam efetivamente da responsabilidade das agências de turismo e viagens, com objetivo de se ter em 
mente: qual é o entendimento do Superior Tribunal de Justiça acerca da responsabilização das referidas empresas em ocorrências diárias nos contratos de transporte aéreo?

\title{
2 DA EVOLUÇÃO HISTÓRICA DA RESPONSABILIDADE CIVIL
}

A evolução histórica é ponto de partida para análise dos inúmeros institutos jurídicos existentes, uma vez que permite a compreensão da evolução e aprimoramento dos institutos ao longo dos anos, séculos e gerações. Além disso, é através da historicidade que se chega ao marco inicial de um regime jurídico.

Os doutrinadores Nelson Rosenvald, Cristiano Chaves de Farias e Felipe Peixoto Braga Netto trazem uma reflexão lapidar acerca da importância da reflexão da evolução histórica:

\begin{abstract}
A análise histórica permite a compreensão de muitas coisas: se considerada no interior de um instituto jurídico, teremos acesso à origem etimológica, aos conceitos e à evolução do tema; se considerada em sua feição externa, na relação com o ordenamento, compreenderemos a origem das regras, a sua conexão com a estrutura e exigências do mercado e da vida social, e a sua dependência em relação às correntes de pensamento (sobretudo filosófico e religioso) que penetram na bagagem cultural do jurista e orientam o legislador do seu tempo. (ROSENVALD, FARIAS, NETTO, 2016, p. 54).
\end{abstract}

A responsabilidade civil surge na frase Pré-Romana, na qual a vingança particular era aplicada como forma de justiça, tanto nas relações físicas quanto patrimoniais.

A forma de responsabilização foi chamada de Lei de Talião, que passou por duas fases no que tange a responsabilidade do autor do ilícito, sendo a primeira ceivada na própria origem e na vingança e a segunda na compensação pecuniária e na transação entre as partes.

Há, porém, na própria lei mencionada, perspectivas da evolução do instituto, ao conceber a possibilidade de composição entre vítima e ofensor, evitando-se a aplicação da pena de Talião. Assim, em vez de impor que o autor de um dano a um membro do corpo sofra a mesma quebra, por força de uma solução transacional, a vítima receberia, a seu critério e a título de poena, uma importância em dinheiro ou outros bens. (STOLZE, FILHO, 2019, p. 58).

Com o tempo a Lei do Talião sofreu alterações e mudou a concepção acerca da responsabilização civil, porém foi através da Lex Aquilia que o instituto ganhou o nome jurídico de "responsabilidade civil delitual ou extracontratual" (FILHO, GAGLIANO, 2019, p. 62). 
A Lex Aquilia foi responsável pela criação da tese da responsabilização do agente pelo dano efetivamente causado a vítima, sem a estipulação de multas ou parâmetros alheios ao que foi perdido pelo lesado.

Neste sentido, a responsabilidade civil deixa de ser uma forma de penalização do sujeito e passa a ser o meio adequado para o ressarcimento da diminuição patrimonial da vítima. É neste sentido que há a separação do direito civil e penal no âmbito das responsabilidades.

A legislação aquiliana foi responsável pela criação do elemento culpa na responsabilização do agente e influenciou inúmeros ordenamentos jurídicos, tais como o Código de Napoleão e Código Civil Brasileiro de 1916.

No âmbito do ordenamento jurídico brasileiro, Figueiredo e Figueiredo (2015) relatam que a Constituição do Império (1824) determinou a criação dos códigos Civil e Penal. O Código Criminal, criado em 1830, foi o responsável pela tutela da responsabilidade civil, a partir do reconhecimento de um ato ilícito.

Posteriormente, promulgou-se o Código Civil de 1916 e a responsabilidade civil passou a ser subjetiva, "passando a exigir prova de culpa ou dolo do agente, autor do dano, como requisito de responsabilização". (FIGUEIREDO, FIGUEIREDO, 2015, p. 300).

Por fim, após a massificação das relações jurídicas, inclusive com o crescimento das relações de consumo, o Código Civil de 2002 adota a teoria do risco como elemento tangente a responsabilidade civil.

É neste sentido que surge a responsabilidade objetiva, correlacionada ao princípio da teoria do risco pelos doutrinadores Luciano Figueiredo e Roberto Figueiredo: "Se uma determinada atividade é capaz, em tese, de causar dano a alguém por ensejar perigo abstrato, o risco há de ser assumido por quem a executa, havendo dever de ressarcimento, independente da aferição de dolo ou culpa”. (FIGUEIREDO, FIGUEIREDO, 2015, p. 302).

Encerrada a breve análise histórica, como fonte de introdução para a tese aqui proposta, passa-se ao estudo dos princípios basilares do Código de Defesa do Consumidor.

\section{DOS PRINCÍPIOS DO CÓDIGO DE DEFESA DO CONSUMIDOR}

\subsection{Princípio da Transparência}


O Princípio da Transparência é tutelado no artigo 4º , caput da Lei 8.078/90 (Código de Defesa do Consumidor).

Este princípio se relaciona, integralmente, com o dever de informação acerca dos produtos e serviços levados ao mercado de consumo.

$\mathrm{Na}$ atual conjuntura, o fornecedor passou a ser responsável pela informação completa de seus produtos, afastando o dever do consumidor em buscar informação sobre o produto ou serviço no qual ansiava.

De acordo com a doutrinadora Claudia Lima Marques, houve uma inversão dos papéis no momento de contratação e os consumidores passaram a ter o direito objetivo de serem amplamente informados no momento de adquirir um produto ou contratar um serviço.

De outro lado, segundo Marques (2016) o fornecedor, anteriormente em posição confortável, passou a ser obrigado a praticar ações diretas de informação sobre os produtos e serviços disponibilizados.

No mesmo sentido, acrescenta:

\begin{abstract}
O consumidor passou a ser titular de um direito subjetivo à informação, e, por outro lado, o fornecedor passou a ter o dever de informar de forma clara e precisa acerca de todas as características dos produtos ou serviços, art. $6^{\circ}$, III e 46 do CDC.

A expressão latina caveat emptor (acautele-se o comprador) na qual a responsabilidade era toda do comprador, já que o vendedor não garantiria o produto, é superada pelo princípio do caveat vendictor, no qual o dever de informar passa a ser do fornecedor. (MARQUES, 2016, p. 123).
\end{abstract}

Então, o fornecedor foi obrigado a apresentar o máximo de informações sobre o produto e serviço ofertado, uma vez que o contrato de consumo se forma a partir da oferta do fornecedor, que não pode se eximir no cumprimento, exceto através de disposição legal expressa.

"Pretendeu, assim, o legislador evitar qualquer tipo de lesão ao consumidor, pois, sem ter conhecimento do conteúdo do contrato, das obrigações que estará assumindo, poderia vincular-se a obrigações que não pode suportar ou que simplesmente não deseja”. (MARQUES, 2016, p. 815).

“A ideia central é possibilitar uma aproximação e uma relação contratual mais sincera e menos danos entre consumidor e fornecedor”. (MARQUES, 2016, p. 814).

Portanto, o princípio da transparência garante ao consumidor a execução do contrato que lhe foi oferecido, podendo ser o cumprimento da oferta compulsório, nos termos legais. Neste sentido, o princípio possibilita uma aproximação autêntica entre os contratantes, afastando possíveis danos. 


\subsection{Princípio da Confiança}

O princípio da confiança se relaciona diretamente com o princípio da transparência, visto que se trata do depósito de confiança do consumidor junto ao contrato, produto ou serviço ofertado pelo fornecedor.

É através do princípio da confiança que o consumidor tem sensação de garantia que o produto adquirido e o serviço prestado são efetivamente seguros e legais.

Preleciona Oliveira (2017) que a quebra do princípio da confiança se relaciona ao mercado de industrialização de produtos ilegais ou falsificados, , pois não oferecem segurança e garantia aos consumidores.

Por fim, "a teoria da qualidade é um dos principais aspectos dessa confiança ao determinar responsabilidade pelos vícios ou defeitos dos produtos ou serviços ou impor um padrão mínimo de qualidade'. (OLIVEIRA, 2017, p. 124).

\subsection{Princípio da Indisponibilidade de Aplicação das Normas de Direito do Consumidor}

A Constituição Federal de 1988 classificou os direitos do consumidor como matérias de direitos fundamentais e ordenou o Poder Legislativo a editar um projeto de lei que tivesse o escopo de um código de proteção aos direitos do consumidor.

Desta feita, as normas de direito do consumidor têm força normativa de ordem pública, nas quais o aplicador das Direito deve reconhecer direitos e deveres de ofício nas relações que envolvam consumidores e fornecedores.

Acerca da constitucionalidade dos direitos dos consumidores, a obra de Claudia Lima Marques, Antonio Herman V. Benjamin e Leonardo Roscoe Bessa expõe:

O direito do consumidor seria, assim, o conjunto de normas e princípios especiais que visam cumprir com este triplo mandamento constitucional: 1) de promover a defesa dos consumidores $[\ldots]$; 2) de observar e assegurar como princípio geral da atividade econômica, como princípio imperativo da ordem econômica constitucional, a necessária 'defesa' dos sujeitos de direitos 'consumidor' [...]; e 3 ) de sistematiczar e ordernar esta tutelas especial infraconstitucionalmente através de um Código (microcodificação), que reúna e organize as normas tutelas, de direito privado e público, com base na ideia de proteção do sujeito de direitos (e não da relação de 
consumo ou do mercado de consumo), um código de proteção e defesa do ‘consumidor’ [...].(BENJAMIN, MARQUES, BESSA, 2009, p. 27)

Portanto, as normas de proteção dos direitos dos consumidores não devem ser afastadas nos contratos de consumo, embora o Superior Tribunal de Justiça tenha decidido pela relativização em alguns contratos consumeristas.

\subsection{Princípio da boa-fé}

Os princípios da boa-fé e da transparência são considerados como os mais importantes para as relações de consumo, pois estão intrinsicamente relacionados ao modo de despertar o desejo de consumir potencialmente, exercido por meio da publicidade.

"A publicidade é tida como uma ferramenta capaz de auxiliar na circulação de bens e serviços, contribuindo com a economia e a geração de riquezas”. (BELNOSKI, 2018)

O princípio da boa-fé se constitui como uma forma de harmonização dos interesses entre consumidores e fornecedores, sendo a parte mais vulnerável detentora de uma maior proteção jurídica, desde o momento pré-contratual até o da execução ou formação do contrato.

A boa-fé se manifesta através da subjetividade, sendo denominada boa-fé subjetiva, que se resume "na ausência de conhecimento de determinado fato ou de intenção de prejudicar alguém, geralmente, o estado subjetivo" (OLIVEIRA, 2017, p. 102).

De outro lado, a boa-fé poderá ser objetiva, conceituada por Nelson Rosenvald:

\footnotetext{
O princípio da boa-fé objetiva - circunscrito ao campo do direito das obrigações - é o objeto de nosso enfoque. Compreende ele um modelo de conduta social, verdadeiro standard jurídico ou regra de conduta, caracterizado por uma atuação de acordo com determinados padrões sociais de lisura, honestidade e correção de modo a não frustrar a legítima confiança da outra parte. [...] Esse dado distintivo é crucial: a boa-fé objetiva é examinada externamente, vale dizer que a aferição se dirige à correção da conduta do indivíduo, pouco importando a sua convicção. De fato, o princípio da boafé encontra a sua justificação no interesse coletivo de que as pessoas pautem seu agir pela cooperação e lealdade, incentivando-se o sentimento de justiça social, com repressão a todas as condutas que importem em desvio aos sedimentados parâmetros de honestidade e retidão. Por isso, a boa-fé objetiva é fonte de obrigações, impondo comportamentos aos contratantes, segundo as regras de correção, na conformidade do agir do homem comum daquele meio social. (ROSENVALD, 2009, p. 458)
}

A boa-fé objetiva se consagrou no direito privado e foi reconhecida, inclusive, pelo Código Civil, através dos artigos 113, 187 e 422. 
Portanto, de acordo com o Júlio Moraes Oliveira: “O princípio da boa-fé objetiva importa na exigência do dever de lealdade entre os contratantes com respeito às expectativas legítimas geradas no outro". (OLIVEIRA, 2017, p. 103).

\section{DA OFERTA E PUBLICIDADE NAS RELAÇÕES DE CONSUMO}

\subsection{Os princípios da publicidade}

O Código de Defesa do Consumidor trata da publicidade nas relações de marketing de consumo. De acordo com Júlio Moraes Oliveira: “A publicidade tem um objetivo comercial, de venda do produto, de anúncio para o consumidor" (OLIVEIRA, 2017, p. 257).

O conceito de publicidade, segundo Antônio Herman V. Benjamin, trazido pela American of Advertiging Agencies (AAAA), "publicidade é qualquer forma paga de apresentação impessoal e promoção tanto de ideias, como de bens ou serviços, por um patrocinador identificado”. (BENJAMIN, MARQUES, BESSA, 2009, P. 196).

Pelo que se extrai do artigo 30 do Código de Defesa do Consumidor ${ }^{3}$, a publicidade e informação de produtos e serviços vincula o contrato de consumo. Conforme discutido no tópico do Princípio da Transparência, a proposta comercial é o próprio contrato de consumo e o fornecedor está adstrito ao exposto ao consumidor.

Trata-se, aqui, do princípio da vinculação, que possui como efeitos principais, para a doutrinador Morais (2017), impõe ao fornecedor cumprir o ofertado e engloba o contrato. Além dos efeitos previstos, o doutrinado expõe que uma das características da oferta e publicidade e a irretratabilidade.

Insta salientar que o Direito do Consumidor não proíbe a prática do puffing - exagero na apresentação de serviços -, vez que se trata de publicidade meramente subjetiva. "Entretanto, se a publicidade puder ser aferida em um, determinado contexto, aí não se pode falar mais em puffing e, neste caso, a publicidade vai vincular”. (OLIVEIRA, 2017, p. 259).

\footnotetext{
${ }^{3}$ Art. 30. Toda informação ou publicidade, suficientemente precisa, veiculada por qualquer forma ou meio de comunicação com relação a produtos e serviços oferecidos ou apresentados, obriga o fornecedor que a fizer veicular ou dela se utilizar e integra o contrato que vier a ser celebrado.
} 
Outro princípio relacionado a publicidade é da lealdade publicitária. De acordo com as lições Oliveira (2017), o princípio busca a vedação de abusos no ambiente publicitário, a concorrência desleal e utilização indevida de inventos e criações industriais no mercado de consumo.

Destaca-se o princípio da identificação da publicidade como o responsável pela publicidade identificada, ou seja, que permita ao consumidor a compreensão fácil acerca do produto ou serviço comercializado.

Portanto, em matéria consumerista é de suma importância o estudo da publicidade, uma vez que vincula o fornecedor e obriga a cumprir com aquilo exposto. Vale ressaltar que as agências de turismo podem veicular os serviços e promoções por diversos meios e não há alteração das normas de consumo pela natureza do serviço. Neste sentido, respeitar as normas consumeristas é imprescindível na prestação de serviço de intermediação de passagens aéreas e pacotes turísticos.

\subsection{O ilícito civil na publicidade}

Passadas as considerações acerca do princípio da boa-fé, se faz necessário um breve estudo sobre a publicidade como ilícito civil, sendo subdividida no Código de Defesa do Consumidor entre a publicidade enganosa e publicidade abusiva.

A publicidade enganosa é conceituada no artigo 37 , parágrafos $1^{\circ}$ e $3^{\circ}$ do Código de Defesa do Consumidor:

Art. 37. É proibida toda publicidade enganosa ou abusiva. $\S 1^{\circ}$ É enganosa qualquer modalidade de informação ou comunicação de caráter publicitário, inteira ou parcialmente falsa, ou, por qualquer outro modo, mesmo por omissão, capaz de induzir em erro o consumidor a respeito da natureza, características, qualidade, quantidade, propriedades, origem, preço e quaisquer outros dados sobre produtos e serviços.

$\S 3^{\circ}$ Para os efeitos deste código, a publicidade é enganosa por omissão quando deixar de informar sobre dado essencial do produto ou serviço. (BRASIL, 1990).

Portanto, em breve análise, a publicidade enganosa é aquela que induz em erro o consumidor, por meio omissivo ou comissivo. Aponta, o doutrinador Leonardo de Medeiros Garcia: 
A publicidade pode ser comissiva, quando afirma algo que, na verdade, não é; como por exemplo, anunciar que determinado veículo é o mais econômico da categoria quando existe outro mais econômico; ou omissiva, quando não informa sobre algo fundamental ('essencial') do produto ou serviço. (GARCIA, 2013, p. 297).

Na publicidade enganosa não se aufere análise de dolo ou culpa, sendo caracterizada pelo erro gerado para o consumidor, conforme pontua Leonardo de Medeiros Garcia: "A análise da indução ao será objetiva, ou seja, independente da intenção do fornecedor”. (2013, p. 296).

No que tange a responsabilidade na cadeia dos fornecedores, julgou a Ministra Nancy Andrighi: "É solidária a responsabilidade entre aqueles que veiculam publicidade enganosa e os que dela se aproveitam”. (STJ, 2014)

No que tange aos contratos de comercialização de passagens aéreas pelas empresas de turismo, o consumidor não está diante de uma situação que cause um erro relevante, visto que do momento da escolha dos trechos de viagem e companhia aérea até o recebimento do bilhete, o consumidor está ciente de todas as peculiaridades do serviço aéreo e da viagem que irá fazer.

Por fim, de outro lado, o artigo 37 , parágrafo $2^{\circ}$ do Código de Defesa do Consumidor, conceitua como publicidade abusiva:

Art. 37. É proibida toda publicidade enganosa ou abusiva.

$\S 2^{\circ}$ É abusiva, dentre outras a publicidade discriminatória de qualquer natureza, a que incite à violência, explore o medo ou a superstição, se aproveite da deficiência de julgamento e experiência da criança, desrespeita valores ambientais, ou que seja capaz de induzir o consumidor a se comportar de forma prejudicial ou perigosa à sua saúde ou segurança. (BRASIL, 1990).

A doutrinadora Claudia Lima Marques classifica como publicidade abusiva: “(...) a publicidade antiética, que fere a vulnerabilidade do consumidor, que fere os valores sociais básicos, que fere a própria sociedade como um todo" (MARQUES, 2016, p. 913).

Neste mesmo raciocínio:

\begin{abstract}
A publicidade abusiva, por sua vez, é aquela que fere a vulnerabilidade do consumidor, podendo ser até mesmo verdadeira, mas que, pelos seus elementos ou circunstâncias, ofendem valores básicos de toda a sociedade. $\mathrm{O} \S 2^{\circ}$ do artigo elenca, de modo exemplificativo, uma série de publicidades abusivas, como a que apresenta de alguma forma de discriminação, que incita a violência, que explora o medo ou a superstição, a antiambiental (sic), a indutora de insegurança, a que a aproveita da hipossuficiência da criança etc. (GARCIA, 2013, p. 298).
\end{abstract}

Como exemplo citado por Garcia (2013), se destaca uma propaganda de uma marca específica de tênis, na qual uma criança destruía um certo tênis com objetivo de forçar os pais a realizarem a compra de um novo tênis da marca específica. 
Portanto, a publicidade abusiva é aquela que ultrapassa o limite contratual entre o fornecedor e os potenciais consumidores e acaba afetando uma gama de sujeitos, de modo negativo, abusivo, preconceituoso e violento.

\section{A RELAÇÃO JURÍDICA DE CONSUMO}

A relação de consumo se divide na conceituação de quatro elementos básicos: a) consumidor; b) fornecedor; c) produtos; e, d) serviços.

Portanto, para que se aplique a legislação consumerista é de suma importância que se entenda os conceitos de cada elemento e, principalmente, se entenda os titulares da relação jurídica de consumo, ora os consumidores e fornecedores.

O passo inicial do estudo se dá ao sujeito de direito tutelado pela legislação consumerista, ora o consumidor. A definição de consumidor é trazida no artigo $2^{\circ}$ do Código de Defesa do Consumidor.

Art. $2^{\circ}$ Consumidor é toda pessoa física ou jurídica que adquire ou utiliza produto ou serviço como destinatário final.

Parágrafo único. Equipara-se a consumidor a coletividade de pessoas, ainda que indetermináveis, que haja intervindo nas relações de consumo. (BRASIL, 1990).

De acordo com Leonardo de Medeiros Garcia:

Sendo assim, são três os elementos que compõem o conceito de consumidor segundo a redação supracitada. O primeiro deles é o subjetivo (pessoa física ou jurídica), o segundo é o objetivo (aquisição de produtos ou serviços) e o terceiro e último é o teleológico (a finalidade pretendida com a aquisição do produto ou serviço) caracterizado pela expressão destinatário final (GARCIA, 2013, p. 28).

A doutrina e jurisprudência, por muito tempo, divergiu acerca do elemento da teleologia, uma vez que o conceito de destinatário final passou a ser explicado por diversas teorias. Cumpre expor e discutir acerca das três teorias mais relevantes para o direito do consumidor, quais sejam a maximalista, finalista e finalista mitigada.

Segundo Claudia Lima Marques, a corrente maximalista:

Destinatário final seria o destinatário fático do produto, aquele que o retira do mercado e o utiliza, o consome, por exemplo, a fábrica de toalhas que compra algodão para transformar, a fábrica de celulose que compra carros para o transporte dos visitantes, 
o advogado que compra uma máquina de escrever para o seu escritório, ou mesmo o Estado quando adquire canetas para uso nas repartições e, claro, a dona de casa que adquire produtos alimentícios para a família. (MARQUES, 2016, p. 308).

De outro lado, a teoria finalista defende que o destinatário final é aquele que "retira o produto do mercado e dá a ele uma destinação final de uso, isto é, o consome na cadeira produtiva”. (OLIVEIRA, 2017, p. 138).

Acrescenta -se: "A teoria finalista pura retira do conceito de consumidor a rela ao existente entre dois profissionais, excluindo a pessoa jurídica”. (OLIVEIRA, 2017, p. 138).

Portanto, para esta teoria, o consumidor final é essencialmente pessoa física que não recoloca o produto ou serviço adquirido na cadeia de consumo.

A teoria finalista mitigada busca amenizar a definição finalista pura, uma vez que passa a analisar a vulnerabilidade para a verdadeira definição do sujeito de direitos na ordem de consumo. É a partir da mitigação da teoria finalista que o Direito do Consumidor passa a ser fonte de proteção para pessoas jurídicas em situação de vulnerabilidade.

Acerca da vulnerabilidade Benjamin, Marques e Bessa (2009) resumem três tipos: técnica, jurídica e fática.

"A vulnerabilidade técnica seria aquela na qual o comprador não possui conhecimentos específicos sobre o produto ou serviço, podendo, portanto, ser mais facilmente iludido no momento da contratação". (GARCIA, 2013, p. 32).

A vulnerabilidade jurídica, conforme Marques (2016), é a que demonstra que o consumidor não possui conhecimento técnico-jurídico, financeiro, contábil, etc. Desta feita, a própria concepção da relação jurídica gera vulnerabilidade do contratante.

De acordo com Benjamin, Marques e Bessa (2009), a vulnerabilidade fática ou real é analisada do ponto de vista do fornecedor, no qual se demonstra substancialmente superior ao consumidor, devido ao seu poder econômico, jurídico ou político.

O Superior Tribunal de Justiça tem aplicado a teoria finalista mitigada e permite a incidência das leis consumeristas para pessoas jurídicas que apresentem vulnerabilidade perante o fornecedor, conforme julgado a seguir exposto:

PROCESSUAL CIVIL. AGRAVO REGIMENTAL NO AGRAVO EM RECURSO ESPECIAL. SERVIÇO DE RASTREAMENTO E COMUNICAÇÃO DE DADOS. FALHA. ROUBO DE VEÍCULO. RESCISÃO CONTRATUAL. 1. OFENSA AOS ARTS. 165 E 535 DO CPC. NÃO OCORRÊNCIA. TEMAS APRECIADOS PELAS INSTÂNCIAS DE ORIGEM. 2.APLICAÇÃO DO CDC. RELAÇÃO DE CONSUMO. TEORIA FINALISTA MITIGAÇÃO. 3.RESPONSABILIDADE. NEXO CAUSAL. IMPOSSIBILIDADE DE ANÁLISE. SÚMULAS N. 5 E 7 DO 
STJ. 4. DISSÍDIO JURISPRUDENCIAL. IMPOSSIBILIDADE. NOVA ANÁLISE DA SITUAÇÃO FÁTICA. 5. AGRAVO IMPROVIDO.

1. Não viola os arts. 165 e 535 do CPC o acórdão que, integrado pelo julgamento proferido nos embargos de declaração, se pronuncia de forma suficiente para a solução da controvér (STJ, 2015)sia deduzida nas razões recursais.

2. A jurisprudência desta Corte Superior tem mitigado a teoria finalista para aplicar a incidência do Código de Defesa do Consumidor nas hipóteses em que a parte, pessoa física ou jurídica, apesar de não ser tecnicamente a destinatária final do produto ou serviço, se apresenta em situação de vulnerabilidade.

3. O acórdão recorrido concluiu estarem configurados os elementos caracterizadores da responsabilidade civil, bem como que a recorrente foi a única responsável pela falha na prestação do serviço, amparado nos dados do contrato e no acervo fáticoprobatório dos autos. Assim, a revisão do julgado de origem exigiria o revolvimento das cláusulas pactuadas entre as partes e das circunstâncias de fato pertinentes ao caso, o que não se admite em recurso especial, diante da aplicação dos enunciados n. 5 e 7 da Súmula desta Corte.

4. Quanto ao dissídio jurisprudencial, tendo o Tribunal local concluído com base no conjunto fático-probatório, impossível se torna o confronto entre o paradigma e o acórdão recorrido, uma vez que a comprovação do alegado dissenso reclama consideração sobre a situação fática própria de cada julgamento, o que não é possível de ser feito nesta via excepcional, por força da Súmula n. 7 deste Tribunal Superior.

5. Agravo regimental a que se nega provimento. (STJ, 2015)

O consumidor é equiparado na legislação em mais três momentos, conforme brevemente analisado a seguir

Nos termos do artigo $2^{\circ}$, parágrafo único do Código de Defesa do Consumidor, é considerado consumidor equiparado a coletividade de pessoas que haja intervindo na relação de consumo. De acordo com Júlio Moraes Oliveira: “O ponto de partida da extensão do campo de aplicação do conceito se deu em grande parte porque muitas pessoas, mesmo não sendo consumidores stricto sensu, poderiam se atingidas ou prejudicas pelas atividades dos fornecedores". (OLIVEIRA, 2017, p. 148).

Conforme artigo 17 da Lei 8.078/90, são consumidores as vítimas dos fatos do serviço. Conclui Júlio Moraes Oliveira que o artigo em análise "alcança aquelas pessoas que não são consumidoras no sentido estrito do termo, mas que, por alguma razão, estavam presentes ou sofreram os efeitos do acidente de consumo" (OLIVEIRA, 2017, p. 153).

Como exemplo, destaca-se a decisão do Superior Tribunal de Justiça que entendeu que existe relação de consumo no caso de uma aeronave que caiu sobre casa das vítimas. ${ }^{4}$

\footnotetext{
${ }^{4}$ Vide: CÓDIGO DE DEFESA DO CONSUMIDOR. ACIDENTE AÉREO. TRANSPORTE DE MALOTES. RELAÇÃO DE CONSUMO. CARACTERIZAÇÃO. RESPONSABILIDADE PELO FATO DO SERVIÇO. VÍTIMA DO EVENTO. EQUIPARAÇÃO A CONSUMIDOR. ARTIGO 17 DO CDC.

I - Resta caracterizada relação de consumo se a aeronave que caiu sobre a casa das vítimas realizava serviço de transporte de malotes para um destinatário final, ainda que pessoa jurídica, uma vez que o artigo $2^{\circ}$ do Código de Defesa do Consumidor não faz tal distinção, definindo como consumidor, para os fins protetivos da lei, "... toda pessoa física ou jurídica que adquire ou utiliza produto ou serviço como destinatário final". Abrandamento do rigor técnico do critério finalista.
} 
Por fim, são considerados consumidores, ex vi artigo 29 do Código de Defesa do Consumidor, "todas as pessoas determináveis ou não, expostas às práticas comerciais de oferta, de contratos de adesão, de publicidade, de cobrança de dívidas, de bancos de dados, sempre que vulneráveis in concreto" (BENJAMIN, MARQUES, BESSA, 2009, p. 79).

Seguindo o estudo subjetivo das relações de consumo, o artigo $3^{\circ}$ 'caput' do Código de Defesa do Consumidor classifica e define quem são os fornecedores.

Art. $3^{\circ}$ Fornecedor é toda pessoa física ou jurídica, pública ou privada, nacional ou estrangeira, bem como os entes despersonalizados, que desenvolvem atividade de produção, montagem, criação, construção, transformação, importação, exportação, distribuição ou comercialização de produtos ou prestação de serviços. (BRASIL, 1990)

A discussão doutrinária acerca da definição do fornecedor paira na amplitude do conceito. Conforme Garcia (2013), a essência do direito do consumidor buscou máxima amplitude do conceito de fornecedor, embora seja crucial a análise da habitualidade para sua determinação. Logo, será considerado fornecedor aquele que desenvolva atividade de modo habitual.

A título de exemplo, exalta o doutrinador, que escola que ofereça curso gratuito se enquadra no conceito de fornecedor, visto que tem como habitualidade a prestação de serviço educacional. De outro lado, agência de viagem que realiza a comercialização de veículo que utilizara para fins próprios não se enquadra, uma vez que não presta serviço de venda de carro.

Vale ressaltar que, conforme disposição legal, o conceito de fornecedor enquadra as pessoas físicas e jurídicas, bem como os entes públicos e despersonalizados.

Por fim, os parágrafos $1^{\circ}$ e $2^{\circ}$ do artigo $3^{\circ}$ revelam os conceitos de produto e serviço para fins de incidência do Código de Defesa do Consumidor.

$\mathrm{O}$ conceito de produto (parágrafo $1^{\circ}$ ) foi definido de forma ampla pelo legislador e abarcou os bens móveis, imóveis, materiais ou imateriais.

De outro lado, o código tutelou que os serviços são atividades fornecidas mediante remuneração. A controvérsia jurisprudencial e doutrinária se deu acerca do termo 'remuneração'.

Acerca da interpretação da expressão remuneração, ressalta-se:

II - Em decorrência, pela aplicação conjugada com o artigo 17 do mesmo diploma legal, cabível, por equiparação, o enquadramento do autor, atingido em terra, no conceito de consumidor. Logo, em tese, admissível a inversão do ônus da prova em seu favor .

Recurso especial provido.

(Recurso Especial 540.235/TO, Relator Ministro Castro Filho, $3^{\mathrm{a}}$ Turma, publicado em 06/03/2006) 
Parece-me que a opção pela expressão "remunerado" significa uma importante abertura para incluir os serviços de consumo remunerados indiretamente, isto é, quando não é o consumidor individual que paga, mas a coletividade (facilidade diluída no preço de todos, por exemplo, no transporte gratuito de idosos), ou quando ele paga indiretamente o 'benefício gratuito' que está recebendo (com a catividade e os bancos de dados positivos de preferências de consumo e marketing direcionado, que significam as milhas, os cartões de cliente preferencial, descontos e prêmios se indicar um 'amigo' ou preencher um formulário). (BENJAMIN, MARQUES, BESSA, 2009, p. 83).

Conforme Michael César Silva e Wellington Fonseca dos Santos: "Pode-se concluir assim que há uma ampla abrangência da lei no que se refere ao que sejam produtos e serviços no âmbito das relações de consumo [...]”. (SILVA, SANTOS, 2013).

\section{A TEORIA DA QUALIDADE NO CÓDIGO DE DEFESA DO CONSUMIDOR}

\subsection{Introdução}

O Código de Defesa do Consumidor tem como teoria da responsabilidade a teoria da qualidade, que divide a responsabilização da cadeia dos fornecedores em duas formas: a incolumidade física-psíquica (vícios de qualidade por inadequação) e econômica do consumidor (vícios de qualidade por insegurança).

Os doutrinadores Antônio Herman V. Benjamin, Claudia Lima Marques e Leonardo Roscoe Bessa (2009, p. 104) exemplificam como conduta que aflige a incolumidade físicapsíquica a colocação de produtos com defeitos que possam causar acidentes aos consumidores. Por óbvio, a responsabilização pelo fato do produto ou serviço é mais rígida, vez que ligada a segurança dos consumidores.

De outro lado, a lesão oriunda de uma cláusula contratual abusiva é um fato típico de prejuízo de ordem patrimonial e econômica, hipótese que se analisa o vício pelo fato do produto ou serviço.

Salienta-se que no estudo do caso em concreto é possível que uma conduta possa chocar com o aspecto físico, moral e econômico, entretanto, para fins de responsabilização, deve-se analisar a preponderância do dano ao consumidor. 


\subsection{A responsabilidade pelo fato do produto e serviço}

O Código de Defesa do Consumidor buscou proteger os consumidores quanto a desconformidade de uma expectativa legítima e a capacidade dos produtos ou serviços de provocar acidentes. A maioria da doutrina optou por conceituar a espécie de responsabilidade pelo fato do produto ou serviço como uma espécie de defeito.

De acordo com Leonardo de Medeiros Garcia: "O defeito é o vício acrescido de um problema extra. O defeito não gera só uma inadequação do produto ou serviço, mas um dano ao consumidor e outras pessoas. Ex.: televisão que explode causando danos às pessoas". (GARCIA, 2013, p. 152).

Insta ressaltar que é possível que um produto ou serviço esteja ceivado de um certo defeito ou vício, mas o Código de Defesa do Consumidor busca proteger os consumidores dos vícios e defeitos que ultrapassam a normalidade dos produtos e serviços.

A doutrina de Júlio Moraes Oliveira classificou os defeitos dos produtos e serviços em três espécies: inerente, adquirida ou exagerada.

A periculosidade inerente se trata daquela previsível pela própria especialidade do produto ou serviço; como exemplo Júlio Moraes Oliveira (2017) cita a faca e o álcool. Aqui, a responsabilidade é afastada, desde que o dano gerado ao consumidor se consubstancie em uma situação de fato normal e previsível.

De outro lado, a periculosidade adquirida é decorrente do defeito do produto, que se subdivide em: (a) defeitos de fabricação, que surgem no momento da produção ou prestação do serviço; (b) defeitos de concepção, ligados ao projeto ou criação do produto ou serviço; e, (c) defeitos de comercialização, relacionados ao momento da oferta e publicidade.

No que tange aos defeitos de comercialização, ressalta-se os produtos que são potencialmente nocivos à saúde, tais como agrotóxicos, inseticidas, produtos inflamáveis e cortantes.

Por fim, as periculosidades inerentes e exageradas se relacionam, muito embora esta apresente um alto grau de nocividade. De acordo com Claudia Lima Marques, Leonardo Roscoe Bessa e Antônio Herman V. Benjamin: "Seu potencial danoso é tamanho que o requisito da previsibilidade não consegue ser totalmente preenchido pelas informações prestadas pelos fornecedores". (BENJAMIN, MARQUES, BESSA, 2009, p. 121).

O Código de Defesa do Consumidor elencou como responsáveis pelo fato do produto e serviço o fabricante, o produtor, o construtor nacional ou estrangeiro, importador, comerciante, 
representante autônomo, preposto, profissionais liberais, órgãos públicos, concessionários, permissionários e patrocinador da publicidade.

A questão que paira na doutrina acerca da responsabilização pelo fato do produto se dá quanto ao comerciante. Deve-se concluir que a reponsabilidade do comerciante com o fabricante, produtor e construtor será estudada de acordo com a especificidade do caso julgado.

Se analisado o texto legal, a conclusão é que o Código de Defesa do Consumidor buscou a responsabilidade solidária, a partir da expressão "igualmente" exposta no artigo 13 da lei.

\footnotetext{
Art. 13. O comerciante é igualmente responsável, nos termos do artigo anterior, quando:

I - o fabricante, o construtor, o produtor ou o importador não puderem ser identificados;

II - o produto for fornecido sem identificação clara do seu fabricante, produtor, construtor ou importador;

III - não conservar adequadamente os produtos perecíveis.

Parágrafo único. Aquele que efetivar o pagamento ao prejudicado poderá exercer o direito de regresso contra os demais responsáveis, segundo sua participação na causação do evento danoso. (BRASIL, 1990).
}

Cumpre salientar que o parágrafo único garantiu ao comerciante o direito de regresso quanto aos demais sujeitos da cadeia de fornecedores.

Ainda no estudo dos defeitos do produto, o Código de Defesa do Consumidor expôs as hipóteses de excludente de responsabilidade pelo fato do produto, conforme artigo 12, parágrafo $3^{\circ}:$

\footnotetext{
Art. 12. O fabricante, o produtor, o construtor, nacional ou estrangeiro, e o importador respondem, independentemente da existência de culpa, pela reparação dos danos causados aos consumidores por defeitos decorrentes de projeto, fabricação, construção, montagem, fórmulas, manipulação, apresentação ou acondicionamento de seus produtos, bem como por informações insuficientes ou inadequadas sobre sua utilização e riscos.

$\S 3^{\circ} \mathrm{O}$ fabricante, o construtor, o produtor ou importador só não será responsabilizado quando provar:

I - que não colocou o produto no mercado;

II - que, embora haja colocado o produto no mercado, o defeito inexiste;

III - a culpa exclusiva do consumidor ou de terceiro. (BRASIL, 1990).
}

As excludentes de responsabilidade civil, de acordo com Júlio Moraes Oliveira (2017), afastam o nexo de causalidade e cabe aos fornecedores a prova de excludente.

Findadas as considerações acerca dos defeitos tangentes aos produtos, passa-se a discorrer acerca dos defeitos na prestação de serviço, objeto do presente trabalho, haja vista que analisa a prestação do serviço de transporte aéreo e a aplicação da excludente de responsabilidade das agências de viagem e turismo. 
A responsabilidade pelo fato do serviço é trazida no artigo 14 do Código de Defesa do Consumidor e não elenca diferenciações na cadeia de fornecimento. Portanto, "o referido artigo usa a expressão genérica 'fornecedor' e inclui na responsabilidade pelo fato dos serviços toda a cadeia de fornecimento". (OLIVEIRA, 2017, p. 210).

Preconiza o artigo $14, \S 1^{\circ}$ do Código de Defesa do Consumidor:

\footnotetext{
Art. 14. O fornecedor de serviços responde, independentemente da existência de culpa, pela reparação dos danos causados aos consumidores por defeitos relativos à prestação dos serviços, bem como por informações insuficientes ou inadequadas sobre sua fruição e riscos.

$\S 1^{\circ} \mathrm{O}$ serviço é defeituoso quando não fornece a segurança que o consumidor dele pode esperar, levando-se em consideração as circunstâncias relevantes, entre as quais: I - o modo de seu fornecimento;

II - o resultado e os riscos que razoavelmente dele se esperam;

III - a época em que foi fornecido. (BRASIL, 1990)
}

Portanto, o defeito na prestação do serviço está relacionado a prestação, concepção ou comercialização do produto.

Segundo Benjamin, Marques e Bessa (2009), o defeito de prestação se dá no momento exato da prestação do serviço; o defeito de concepção ocorre do momento da criação do serviço e na escolha dos métodos de prestação; por fim, o defeito de comercialização está relacionado ao descumprimento do dever de informação.

Por fim, no que tange a responsabilização da cadeira de fornecimento, o próprio Código de Defesa do Consumidor trouxe as hipóteses para exclusão de responsabilidade, bem como de mitigação da responsabilidade objetiva, solidária e integral dos fornecedores.

De acordo com o parágrafo terceiro do artigo 14 da Lei 8.078/90, o fornecedor não é responsabilizado quando demonstrada a inexistência de defeito no serviço e a culpa de terceiros ou do próprio consumidor.

Embora a lei seja restrita, a doutrina estendeu a interpretação e colocou os casos de caso fortuito e força maior como excludentes de responsabilização dos fornecedores.

Por fim, relacionando o tema proposto e a responsabilização pelo fato do serviço, Júlio Moraes Oliveira expõe que "a agência de truísmo que comercializa pacotes de viagens responde solidariamente, nos termos do artigo 14 do Código de Defesa do Consumidor, pelos defeitos na prestação dos serviços que integram o pacote".

\subsection{A Responsabilidade pelo vício do produto ou serviço}


Encerrada a análise dos defeitos do produto, passa-se a discutir acerca do aspecto da incolumidade econômica do consumidor. De acordo com Júlio Moraes Oliveira, "o conceito de vício está atrelado à qualidade do produto, seu elemento básico é a carência de adequação ao fim que se destina”. (OLIVEIRA, 2017, p. 217).

O Código Civil dispõe apenas acerca do vício oculto, denominado redibitório, de modo diverso do Código de Defesa do Consumidor que traz diversas hipóteses de vícios, conforme será discutido de forma breve a seguir.

Expõe Júlio Moraes Oliveira: "Na seara consumerista, a noção dos vícios é bem mais ampla e abarca os vícios aparentes e de fácil constatação, bem como os produtos que estejam em desacordo com as normas regulamentares de fabricação, distribuição ou apresentação" (OLIVEIRA, 2017, p. 217).

O vício aparente ou de fácil constatação, de acordo com Oliveira (2017), é aquele que o consumidor percebe facilmente, seja no momento da compra ou do primeiro uso. Acrescentase que a legislação consumerista não proíbe a venda de produtos com pequenas avarias ou usados, no entanto deve ser de prévio conhecimento do consumidor e não gerar um afastamento da finalidade do produto.

Outro vício do produto, nos termos do artigo 19 do Código de Defesa do Consumidor, é o de quantidade. Destaca-se a responsabilidade solidária de todos os fornecedores envolvidos na relação. Contudo, a regra de solidariedade é afastada e imputada somente ao comerciante, caso este tenha obrigação de realizar a pesagem do produto.

Há, ainda, o vício de informação que, nas lições Oliveira (2017) se trata do vício que se origina da informação deixada de prestar pelo fornecedor. Insta salientar que o vício de informação fere a própria ordem consumerista, visto que fere os princípios basilares aqui trazidos.

Por fim, destaca-se que o consumidor possui algumas opções quando se depara com vícios de produtos ou serviços. Quanto aos produtos, o consumidor poderá optar pela substituição do produto, restituição imediata da quantia paga ou abatimento proporcional do preço, desde que respeitados os prazos e condições.

Quanto aos serviços, são opções a reexecução do serviço a restituição da quantia paga ou o abatimento proporcional do preço, sendo cumpridos os prazos e condições expressas. 


\subsection{Do complexo normativo dos contratos de transporte aéreos}

A regulamentação jurídica do serviço de transporte aéreo se origina do artigo 178 da Constituição Federal, que dispõe:

\footnotetext{
A lei disporá sobre a ordenação dos transportes aéreo, aquático e terrestre, devendo, quanto à ordenação do transporte internacional, observar os acordos firmados pela União, atendido o princípio da reciprocidade. (BRASIL, 1988).
}

Portanto, os contratos de transporte aéreo possuem proteção constitucional e devem ser regulados por legislação infraconstitucional.

No caso do transporte aéreo, por exemplo, o Código Brasileiro de Aeronáutica se incumbiu de expor diretrizes e ordenações acerca do transporte ampla, abrangendo a complexidade que o serviço aéreo brasileiro possui.

Conforme voto da Ministra Nancy Andrighi:

O Código Brasileiro de Aeronáutica não se limita a regulamentar apenas o transporte aéreo regular de passageiros, realizado por quem detém a respectiva concessão, mas todo serviço de exploração de aeronave, operado por pessoa física ou jurídica, proprietária ou não, com ou sem fins lucrativos, s, de forma que seu art. 317, II, não foi revogado e será plenamente aplicado, desde que a relação jurídica não esteja regida pelo CDC, cuja força normativa é extraída diretamente da CF (5º XXXII). (STJ, 2013)

Entretanto, o Código Brasileiro de Aeronáutica conseguiu prever ocorrências específicas no transporte aéreo de pessoas e o Código Civil tipificou os contratos de transporte de pessoas, conforme artigos 730 a 756, se aplicando a estes o transporte aéreo.

Devido ao crescimento de fatos específicos no âmbito aeroportuário e a colocação do consumidor como vulnerável na relação, discutiu-se sobre a possibilidade de aplicação do Código de Defesa do Consumidor nos contratos de transporte aéreo, restando consolidado o entendimento de aplicação do Código de Defesa do Consumidor nos contratos de transporte aéreo de âmbito nacional.

Vale ressaltar que o Código Civil também trouxe regras contratuais dos transportes aéreos, conforme se verifica pelos artigos 730 a 756 do referido diploma. Entretanto, a doutrina e jurisprudência possuem entendimento que há prevalência dos direitos previstos no Código de 
Defesa do Consumidor, uma vez que o Código Civil se trata de lei geral e a legislação consumerista lastro constitucional.

De outro lado, nos contratos de transporte internacional o texto constitucional revela que devem obedecer aos acordos firmados pela União.

Neste sentido, a doutrina e jurisprudência passaram a analisar a aplicabilidade da Convenção de Varsóvia nos contratos aéreos internacionais, principalmente pelo fato do tratado estipular limitação de indenização em casos de má-prestação de serviços da empresa aérea.

O tema ganhou tanta amplitude que o Supremo Tribunal Federal julgou Recurso Extraordinário com Repercussão Geral $n^{\circ}$ 636.331/RJ, que determinou pela aplicação da limitação de indenização por danos morais, em casos de danos a passageiros, bagagens e cargas, nos termos da Convenção de Varsóvia.

Contudo, em recente julgado, no Agravo em Recurso Extraordinário n ${ }^{\circ}$ 166.618/SP, o Supremo Tribunal Federal entendeu que as Convenções de Varsóvia e Montreal possuem prevalência em relação ao Código de Defesa do Consumidor.

Desta feita, pode-se concluir que os contratos de transporte aéreo são tutelados pelas normas do Código de Defesa do Consumidor, Código Civil, Convenção de Montreal e Varsóvia e demais fontes normativas.

\subsection{Das agências de viagens e turismo}

A aplicação do Código de Defesa do Consumidor para as relações jurídicas que envolvam a prestação do serviço de transporte aéreo é uníssona e não há divergência jurisprudencial e da melhor doutrina.

A evolução das relações comerciais foi responsável pelo crescimento de diversas empresas e novos serviços à disposição dos consumidores. Aqui, ressalta-se o surgimento das empresas de viagens e turismo, tuteladas pela Lei 12.974/14.

Os artigos $3^{\circ}$ e $4^{\circ}$ da referida lei expressam os serviços prestados pelas empresas de operações turísticas, ressaltando, conforme inciso I do artigo $3^{\circ}$, a "venda comissionada venda comissionada ou intermediação remunerada na comercialização de passagens, passeios, viagens e excursões, nas modalidades aérea, aquaviária, terrestre, ferroviária e conjugadas". 
Neste sentido, cabe as agências de viagem e turismo a intermediação de passagens aéreas, havendo o devido recebimento pelos serviços, bem como o devido cumprimento do serviço ofertado, nos termos do artigo $9^{\circ}$, inciso I da Lei 12.974/14.

Tratando-se, exclusivamente, do serviço de intermediação, ora a emissão de passagens aéreas, as agências de viagens e turismo estão vinculadas aos elementos essências do bilhete de passagem aérea, não estando correlacionadas aos casos de reponsabilidade e competência única das companhias aéreas, tais como extravio de bagagem ou alteração do horário do voo.

Neste mesmo passo, não há que se falar em descumprimento com a legislação consumerista, uma vez que há tipificação de excludentes de responsabilidade civil no Código de Defesa do Consumidor, bem como a decisão do Superior Tribunal de Justiça afasta a responsabilidade em casos específicos, conforme será discorrido a seguir.

Portanto, conclui-se que o serviço de intermediação de passagens aéreas, prestado pelas agências de viagem e turismo, possui lastro normativo e as questões atinentes a responsabilidade civil das empresas devem ser estudadas com cautela, a fim de evitar um excesso de responsabilização por atos de terceiros.

\section{DA RESPONSABILIDADE CIVIL DAS AGÊNCIAS DE TURISMO}

As agências de turismo ou viagens são tuteladas de acordo com a Lei 12.974/2014 e podem ser denominadas por operadoras turísticas.

$\mathrm{O}$ artigo $3^{\circ}$ da referida lei elenca as atividades privativas das agências de turismo, ressaltando que o mero preenchimento de um dos incisos é suficiente para o enquadramento como agência de turismo, conforme se verifica:

Art. $3^{\circ}$ É privativo das Agências de Turismo o exercício das seguintes atividades: I - venda comissionada ou intermediação remunerada na comercialização de passagens, passeios, viagens e excursões, nas modalidades aérea, aquaviária, terrestre, ferroviária e conjugadas;

II - assessoramento, planejamento e organização de atividades associadas à execução de viagens turísticas ou excursões;

III - (VETADO);

IV - organização de programas, serviços, roteiros e itinerários de viagens, individuais ou em grupo, e intermediação remunerada na sua execução e comercialização; e $\mathrm{V}$ - organização de programas e serviços relativos a viagens educacionais ou culturais e intermediação remunerada na sua execução e comercialização. (BRASIL, 2014) 
As agências de viagem, que prestam o serviço exclusivo de intermediação de passagens aéreas, iniciam a sua relação com os consumidores a partir da oferta de passagens aéreas ou da pesquisa de trechos e voos pelos consumidores. Assim, a vinculação entre as empresas e os consumidores é a disponibilização de bilhetes de passagens aéreas.

Neste sentido, a relação jurídica se encerra a partir do momento que a empresa oportuniza ao consumidor, ora cliente, todos os meios para a realização da viagem, conforme pretensões iniciais.

O serviço de transporte aéreo possui inúmeras peculiaridades e sua organização se divide entre o Poder Público e as companhias aéreas.

O Poder Público possui diversas competências relativas a complexidade do sistema de transporte aéreo, tais como controle do espaço aéreo, auxílio dos passageiros, administração de aeroportos, entre outras inúmeras.

Um dos maiores órgãos do governo federal, responsável pelo complexo sistema de transporte aeronáutico, é o Departamento de Controle do Espaço Aéreo comandado pelo Comando de Aeronáutica.

Ainda, a Agência Nacional de Aviação Civil que é uma das agências reguladoras federais e “(...) foi criada para regular e fiscalizar as atividades da aviação civil e a infraestrutura aeronáutica e aeroportuária no Brasil”. (AGÊNCIA NACIONAL DE AVIAÇÃO CIVIL, 2019).

Neste ínterim, o surgimento de novas empresas no ramo do comércio aéreo gerou uma necessidade de tutela e responsabilização específica, uma vez que a atividade das grandes empresas de transporte aéreo não se compara a de pequenas ou médias agências de turismo.

O judiciário brasileiro possui inúmeras ações que tratam do serviço de transporte aéreo e as inúmeras ocorrências típicas do âmbito aeroportuário, tais como atrasos e cancelamentos de voos, overbooking, extravio de bagagem, etc.

O cerne da presente discussão é: qual a responsabilidade das agências de turismo?

É imprescindível a análise do caso em concreto a fim de se responsabilizar os fornecedores devidamente. Para isto, se analisa a teoria da qualidade e aplicação do artigo 14, parágrafo $3^{\circ}$ do Código De Defesa Do Consumidor.

$\mathrm{Na}$ análise jurisprudencial realizada, as agências de turismo não são responsabilizadas, em casos específicos, nos quais a competência do ato é único e exclusivo das companhias aéreas. 
Conforme se analisa pela jurisprudência a seguir, o STJ entendeu que agência de viagem que comercializou, tão somente, passagem aérea não é responsável pelo cancelamento do voo, ou seja, pela ausência da prestação do serviço de transporte aéreo.

AGRAVO REGIMENTAL NO RECURSO ESPECIAL. TRANSPORTE AÉREO. INEXECUÇÃO DO SERVIÇO. AÇÃO DE INDENIZAÇÃO. AGÊNCIA DE TURISMO. ILEGITIMIDADE PASSIVA AD CAUSAM RECONHECIDA.

1. A jurisprudência deste Tribunal admite a responsabilidade solidária das agências de turismo apenas na comercialização de pacotes de viagens.

2. No caso, o serviço prestado pela agência de turismo foi exclusivamente a venda de passagens aéreas, circunstância que afasta a sua responsabilidade pelo efetivo cumprimento do contrato de transporte aéreo e autoriza o reconhecimento da sua ilegitimidade para figurar no polo passivo da ação indenizatória decorrente de cancelamento de voo.

3. Agravo regimental não provido. (STJ, 2014).

Vale ressaltar, conforme princípio da transparência e publicidade, que a agência de turismo é responsável pelo serviço atinente a emissão e envio dos bilhetes de passagem, não sendo plausível a responsabilização pela efetiva prestação do serviço de transporte aéreo.

Neste sentido, conforme teoria da qualidade, há exclusão de responsabilidade da agência de turismo, uma vez que a companhia aérea foi a responsável pelos danos causados ao passageiro.

De outro modo, o STJ possui entendimentos de responsabilização solidárias das agências de turismo e companhias aéreas, desde que o serviço prestado pela agência seja de pacote turístico, fato que vincula o fornecimento de toda uma cadeia de serviços, dentre eles o transporte aéreo, conforme jurisprudências a seguir:

RESPONSABILIDADE CIVIL. INDENIZAÇÃO POR DANOS MORAIS. PACOTE DE VIAGEM INCLUINDO INGRESSOS PARA OS JOGOS DA COPA DO MUNDO DE FUTEBOL. MÁ PRESTAÇÃO DOS SERVIÇOS. LEGITIMIDADE DA AGÊNCIA QUE COMERCIALIZA O PACOTE. ALTERAÇÃO DOS DANOS MORAIS. DESCABIMENTO. 1.- A agência de viagens que vende pacote turístico responde pelo dano decorrente da má prestação dos serviços. 2.- A intervenção deste Tribunal para a alteração de valor de indenização fixado por danos morais se dá excepcionalmente, quando verifica-se exorbitância ou irrisoriedade da quantia estabelecida, o que não ocorre no caso concreto. Agravo Regimental improvido. (STJ, 2009)

RECURSO ESPECIAL. CONSUMIDOR. OFENSA AO ART. 535 DO CPC. NÃOCARACTERIZADA. FALHA NA PRESTAÇÃO DE SERVIÇOS. PACOTE TURÍSTICO.INOBSERVÂNCIA DE CLÁUSULAS CONTRATUAIS. AGÊNCIA DE TURISMO.RESPONSABILIDADE (CÓDIGO DE DEFESA DO CONSUMIDOR, ART. 14). INDENIZAÇÃO. DANOS MATERIAIS.NECESSIDADE DE COMPROVAÇÃO. SÚMULA 7 DO STJ. DANOS MORAISRECONHECIDOS. RECURSO PARCIALMENTE PROVIDO. 1. Não há ofensa ao art. 535 do Código de Processo Civil se o Tribunal a quo decide, fundamentadamente, as questões essenciais ao julgamento da lide. 2. Esta eg. Corte tem entendimento no sentido de que a agência de turismo que comercializa pacotes 
de viagens responde solidariamente, nos termos do art. 14 do Código de Defesa do Consumidor, pelos defeitos na prestação dos serviços que integram o pacote. 3 . No tocante ao valor dos danos materiais, parte unânime do acórdão da apelação, decidiu a eg. Corte a quo que seriam indenizáveis apenas os prejuízos que foram comprovados, o que representa o valor de $\mathrm{R} \$ 888,57$. O acolhimento da tese recursal de que estariam comprovados os demais prejuízos de ordem material relativos ao que foi originalmente contratado demandaria, inevitavelmente, o reexame de fatos e provas, o que esbarra no óbice da Súmula $\mathrm{n}^{\circ} 7 / \mathrm{STJ}$. 4. Já quanto aos danos morais, o v. acórdão recorrido violou a regrado art. $14, \S 3^{\circ}$, II, do CÓDIGO DE DEFESA DO CONSUMIDOR, ao afastar a responsabilidade objetivado fornecedor do serviço. Como registram a r. sentença e o voto vencido no julgamento da apelação, ficaram demonstrados outros diversos percalços a que foram submetidos os autores durante a viagem, além daqueles considerados no v. acórdão recorrido, evidenciando os graves defeitos na prestação do serviço de pacote turístico contratado pelo somatório de falhas, configurando-se, in casu, os danos morais padecidos pelos consumidores. 5 . Caracterizado o dano moral, mostra-se compatível a fixação da indenização em $\mathrm{R} \$$ 20.000,00 (vinte mil reais) para cada autor. Em razão do prolongado decurso do tempo, nesta fixação da reparação a título de danos morais já está sendo considerado o valor atualizado para a indenização pelos fatos ocorridos, pelo que a correção monetária e os juros moratórios incidem a partir desta data. 6. Recurso especial conhecido e parcialmente provido. (STJ, 2011)

Portanto, o STJ possui entendimento uníssono quanto a excludente de responsabilidade das agências de turismo, bem como a ilegitimidade para figurar no polo passivo de uma ação, se demonstrado que o erro advém de prática relativa ao serviço de transporte aéreo.

Neste sentido, não há que se falar em responsabilização de agências de turismo nos casos de overbooking, extravio de bagagem e cancelamentos de voos. Por óbvio, trata-se da regra, sendo a exceção, a responsabilidade solidária nos casos de venda de pacotes turísticos.

Embora a jurisprudência do STJ tenha aplicado a responsabilidade solidária somente em casos específicos, as atuais decisões na primeira instância tendem a responsabilizar toda a cadeia de fornecimento e não aplicar a excludente exposta pela Corte Superior, conforme se analisa pela recente decisão do Tribunal de Justiça de Minas Gerais:

EMENTA: APELAÇ̃̃O CÍVEL. AÇÃO DE INDENIZAÇ̃̃O. EXTRAVIO DE BAGAGEM - RELAÇÃO DE CONSUMO - RESPONSABILIDADE SOLIDÁRIA - CADEIA DE CONSUMO. DANOS MORAIS. CONFIGURADOS. QUANTUM INDENIZATÓRIO. RAZOABILIDADE E PROPORCIONALIDADE. DANOS MATERIAIS. - A relação existente entre as partes é inquestionavelmente uma relação de consumo, na medida em que os litigantes se subsumem perfeitamente aos conceitos jurídicos de consumidor e fornecedor (artigo $2^{\circ}$, caput, e $3^{\circ}$, caput, e $\S 2^{\circ}$, do Código de Defesa do Consumidor)- A responsabilidade dos membros da cadeia de fornecimento é solidária, sendo descabidas, portanto, todos os argumentos que tentam imputar a somente um dos prestadores a responsabilidade exclusiva pelo evento danoso - Sofre lesão a direito de personalidade o consumidor que teve sua mala extraviada em viagem de férias - A fixação do valor da compensação pelos danos morais deve-se considerar a extensão do dano experimentado pela vítima, a repercussão no meio social, a situação econômica da vítima e do agente causador do dano, para que se chegue a uma justa composição, evitando-se, sempre, que o ressarcimento se transforme numa fonte de enriquecimento injustificado ou seja inexpressivo a ponto de não retribuir o mal causado pela ofensa - Havendo efetiva demonstração dos danos materiais, deve esta condenação ser mantida. (TJMG, 2019) 
Conclui-se que há divergências de posicionamentos, sendo necessário uma efetiva análise de todo complexo da relação de consumo envolvida, dos serviços ofertados e propostos aos consumidores, ao modo de fornecimento dos serviços ou produtos, bem como a lesão jurídica pleiteada pelo consumidor no caso em concreto.

\section{CONSIDERAÇÕES FINAIS}

O tema proposto trouxe uma análise jurisprudencial sobre a responsabilidade das agências de turismo nos contratos de transporte aéreo, buscando levar em consideração os aspectos técnicos do serviço ofertado e do complexo normativo que envolve as relações aéreas.

O STJ consolidou entendimento que trata da responsabilização de uma agência de turismo/viagem, entendendo que a solidariedade relativa, aos contratos de consumo, deve ter por base o próprio estudo do caso e análise das nuances fáticas e jurídicas.

Para tanto, entendeu que a responsabilidade da agência de turismo é solidária nos casos de venda de pacotes turísticos, uma vez que abarca uma complexidade de serviços e produtos colocados no próprio mercado de consumo.

O estudo dos princípios das relações de consumo é de suma importância para entendimento da responsabilidade das agências de turismo. A boa-fé objetiva é o patamar principal da presente tese, uma vez que o consumidor deve ser informado de maneira ampla e satisfativa acerca da essencialidade da atividade da agência de turismo.

Neste mesmo sentido, o princípio da transparência é fonte contratual para a relação, fato que vincula a oferta ao seu cumprimento. Portanto, a responsabilização solidária, nos casos de pacotes turísticos, é explicada, uma vez que a agência de turismo se vê na obrigação de cumprir todo o arcabouço de serviços e produtos ofertado.

Conclui-se que o serviço de intermediação de passagens aéreas e comercialização de pacotes turísticos são espécies notórias de contratos de consumo e devem respeitar todo complexo doutrinário, legal e jurisprudencial, a fim de garantir proteção do consumidor e o devido cumprimento dos serviços ofertados.

Entretanto, nos casos de supostos danos alegados pelos consumidores ou situações de aparentes defeitos na prestação dos serviços, é necessário que haja um estudo da própria 
essência da teoria da qualidade e do entendimento jurisprudencial vinculante e aplicado pelos tribunais superiores.

\section{REFERÊNCIAS}

AGÊNCIA NACIONAL DE AVIAÇÃO CIVIL. ANAC. Publicado em 09/05/2019. Fonte: ANAC: http://www.anac.gov.br/A_Anac/institucional

BELNOSKI, Alexsandra Marilac. A Publicidade no Código de Defesa do Consumidor. Publicado em 01/08/2018. Google Chrome. Fonte: Migalhas: https:/www.migalhas.com.br/dePeso/16,MI284819,61044$\mathrm{A}+$ publicidade + no + Codigo + de + Defesa + do + Consumidor

BRASIL. (10 de 01 de 2002). Lei 10.406/2002, Código Civil. Acesso em 13 de 06 de 2019, disponível em Planalto: http://www.planalto.gov.br/ccivil_03/leis/2002/110406.htm

BRASIL. (11 de 09 de 1990). Lei 8.078/90, Código de Defesa do Consumidor. Acesso em 13 de 06 de 2019, disponível em Planalto: http://www.planalto.gov.br/ccivil_03/leis/18078.htm

BRASIL. (15 de 05 de 2014). Lei 12.974/2014. Acesso em 13 de 06 de 2019, disponível em Planalto: http://www.planalto.gov.br/CCIVIL_03/_Ato2011-2014/2014/Lei/L12974.htm

BRASIL. (22 de 09 de 1988). Constituição Federal. Acesso em 13 de 06 de 2019, disponível em Planalto: http://www.planalto.gov.br/ccivil_03/constituicao/constituicao.htm

FARIAS, Cristiano Chaves. ROSENVALD, Nelson. NETTO, Felipe Peixoto Braga. Curso de direito civil: responsabilidade civil. $3^{\text {a }}$ ed. rev. e atual. Salvador: Editora JusPodivm. 2016

FIGUEIREDO, Luciano. FIGUEIREDO, Roberto. Direito civil: direito das obrigações e responsabilidade civil. $4^{\mathrm{a}}$ ed. ver. amp. atual. Salvador. Editora JuvPodivm.2015

FIUZA, Cesar. Direito Civil: Curso Completo. 14ª ed. Belo Horizonte: Del Rey Editora. 2010.

GAGLiANO, Pablo Stolze. FILHO, Rodolfo Pamplona. Novo curso de direito civil, v.3: responsabilidade civil. $17^{\mathrm{a}}$ ed. rev. amp. atual. São Paulo: Saraiva Educação. 2019

GARCIA, Leonardo de Medeiros. Curso do consumidor: código comentado e jurisprudência. $10^{\mathrm{a}}$ ed. rev. amp. atual. Salvador: Editora JusPodivm. 2014

JÚNIOR, Humberto Theodoro. Direitos do consumidor: a busca de um ponto de equilíbrio entre as garantias do CÓDIGO DE DEFESA DO CONSUMIDOR e os princípios gerais do Direito Civil e do Direito Processual Civil. $8^{\text {a }}$ ed. Rio de Janeiro: Forense. 2013

MARQUES, Claudia Lima. Contratos no Código de Defesa do Consumidor: o novo regime das relações contratuais. $8^{\mathrm{a}}$ ed. rev. ampl. atual. São Paulo: Editora Revista dos Tribunais. 2016. 
OLIVEIRA, Júlio Moraes. Curso de Direito do Consumidor completo. $4^{\mathrm{a}}$ ed. Belo Horizonte: Editora D'Plácido. 2017.

SILVA, Michael César. SANTOS, Wellignton Fonseca dos. O Direito do Consumidor nas Relações de Consumo Virtuais. Revista Eletrônica de Direito do Centro Universitário Newton Paiva. Publicação em 8/10/2013. Acesso em 29/05/2019, disponível em http://npa.newtonpaiva.br/direito/?p=1294

STJ. (15 de 12 de 2014). AgRg no REsp 1453920/CE, Relator Ricardo Villas Bôas Cueva, DJ 09/12/2014. Acesso em 12 de 06 de 2019, disponível em LEXML: https://www.lexml.gov.br/urn/urn:lex:br:superior.tribunal.justica;turma.3:acordao;resp:201412-09;1453920-1403791

STJ. (16 de 11 de 2014). REsp 327257/SP. Relatora Ministra Nancy Andrighi. DJ: 22/06/2004. Acesso em 07 de 06 de 2019, disponível em JusBrasil: https://stj.jusbrasil.com.br/jurisprudencia/150968/recurso-especial-resp-327257?ref=serp

STJ. (21 de 05 de 2015). AgRg no AREsp 601.234/DF. Relator Ministro Marco Aurélio Bellizze. DJ: 12/05/2015. Acesso em 29 de 05 de 2019, disponível em JusBrasil: https://stj.jusbrasil.com.br/jurisprudencia/190526500/agravo-regimental-no-agravo-emrecurso-especial-agrg-no-aresp-601234-df-2014-0264397-3

STJ. (23 de 11 de 2009). AgRg no REsp 850768/SC, Relator Minsitro Sidnei Beneti, DJ 27/10/2009. Acesso em 12 de 06 de 2019, disponível em JusBrasil: https://stj.jusbrasil.com.br/jurisprudencia/5707861/agravo-regimental-no-recurso-especialagrg-no-resp-850768-sc-2006-0101165-0?ref=juris-tabs

STJ. (27 de 06 de 2013). REsp: 1202013/SP. Relatora Ministra Nancy Andrighi. DJ: 18/06/2013. Acesso em 07 de 06 de 2019, disponível em JusBrasil: https://stj.jusbrasil.com.br/jurisprudencia/23540598/recurso-especial-resp-1202013-sp-20100126678-7-stj?ref=serp

STJ. (27 de 10 de 2011). REsp 888751, Relator Ministro Raul Araújo, DJ 25/10/2011. Acesso em 12 de 06 de 2019, disponível em JusBrasil: https://stj.jusbrasil.com.br/jurisprudencia/21060522/recurso-especial-resp-888751-ba-20060207513-3-stj?ref=juris-tabs

TJMG. (05 de 04 de 2019). Apelação Cível 10079120700350001, Relator Desembargador Pedro Aleixo, DJ 25/03/2019. Acesso em 12 de 06 de 2019, disponível em JusBrasil: https://tjmg.jusbrasil.com.br/jurisprudencia/695229255/apelacao-civel-ac-10079120700350001$\mathrm{mg}$ ?ref=juris-tabs 